\title{
Cellulose Buccoadhesive Film Bearing Glimepiride: Physicomechanical Characterization and Biophysics of Buccoadhesion
}

\author{
Jaya Gopal Meher, ${ }^{1,2}$ Magdaline Tarai, ${ }^{1}$ Ansuman Patnaik, ${ }^{1}$ Paresh Mishra, ${ }^{1}$ and Narayan Prasad Yadav $^{2,3}$
}

Received 29 July 2015; accepted 22 September 2015; published online 9 October 2015

\begin{abstract}
The present study aimed to develop buccoadhesive film of glimepiride with unique combination of polymers and to investigate its effect(s) on physicomechanical parameters, drug-release, and permeation of films. Drug-polymer interaction was examined by FTIR and DSC analysis. Films were prepared by solvent casting technique and characterized for film strength $(320 \pm 8.5 \mathrm{~g}, 28.98 \pm 2.00 \mathrm{~mJ})$, buccoadhesive strength $(28.8 \pm 1.37 \mathrm{~g}, 3.04 \pm 0.32 \mathrm{~mJ})$, and tensile strength $(260 \pm 6.88 \mathrm{~g}, 18.00 \pm 0.44 \mathrm{~mJ})$ by new instrumental techniques. Increase in polymer concentration augmented zeta potential of polymeric matrix-mucin mixture and exhibited strong buccoadhesion (electrical theory). Buccoadhesion was also influenced by particle size (adsorption theory) and swelling (wetting theory). Erosion behavior of films was observed in swelling and SEM studies. Film GM4 exhibited $98 \pm 2 \%$ in vitro drug release and $85 \pm 8 \%$ ex vivo drug permeation in $12 \mathrm{~h}$ with controlled diffusion mechanism. Films were compatible with oral probiotic microorganisms. Stability studies revealed no significant $(P<0.05)$ variation in physicomechanical characteristics.
\end{abstract}

KEY WORDS: biophysics of buccoadhesion; buccoadhesive film; buccoadhesive strength; buccocompatibility; glimepiride.

\section{INTRODUCTION}

Buccoadhesive systems are one of the novel formulation techniques, where polymers play a central role. These formulations (films and patches) are the representative systems of transdermal patches and have many advantages viz. dose accuracy, small and compact size, local or systemic action, swift absorption of the drug, ease of withdrawal in urgent situation, controlled and/or sustained release, prevention of gastric degradation or first-pass effect, and comparatively better stability than other buccoadhesive systems (cream, gel, ointment) (1). Experimental evidences on better therapeutic efficacy of drug molecules viz. carvedilol, lidocaine, salbutamol, and miconazole as buccoadhesive films/patches have been referenced in scientific texts $(2,3)$. Moreover, mucoadhesive preparations included in the European Pharmacopoeia 7.4 (2012) have encouraged researchers to utilize the advantages of the technique in drug delivery research (4).

Electronic supplementary material The online version of this article (doi:10.1208/s12249-015-0419-5) contains supplementary material, which is available to authorized users.

\footnotetext{
${ }^{1}$ Indira Gandhi Institute of Pharmaceutical Sciences, IRC Village, Bhubaneswar, 751015, India.

${ }^{2}$ CSIR-Central Institute of Medicinal and Aromatic Plants (CSIRCIMAP), Lucknow, 226015, UP, India.

${ }^{3}$ To whom correspondence should be addressed. (e-mail: npyadav@gmail.com)
}

In the present research, substantial efforts have been put to develop films and to explore physicomechanical parameters of films, implementing new instrumental techniques, which assure reproducible results than age old methods used in the evaluation of film strength, buccoadhesive and tensile strength of films/patches. Glimepiride was chosen as a model drug as it exhibits very poor aqueous solubility $(0.001908 \mathrm{mg} / \mathrm{mL})$ leading to slow dissolution in the gastrointestinal environment and poor bioavailability. In order to overcome this problem, it has been delivered via transdermal route and a significant reduction in blood glucose level was observed in comparison to oral delivery (5). To date, glimepiride has not been explored for buccal delivery although it is one of the suitable candidate for buccal route owing to its low dose (1-4 mg), low molecular weight (490.61), and high partition coefficient (3.5) (6). A combination of new (Ultrez-21, Pluronic F68) and conventional polymers (Methocel, Eudragit RL100) was chosen for development of buccoadhesive films. Methocel was employed as the central rate controlling polymer in the proposed matrix system, and the effect of combinations of polymers was scrutinized for different film parameters. Although many buccal films have been reported in literature employing various combinations of synthetic/semisynthetic as well as natural polymers, the amalgamation we have selected is novel and has not been reported for glimepiride to the best of our knowledge. A brief discourse of biophysics of buccoadhesion based on various proposed theories of bioadhesion is also discussed with the findings of zeta potential, particle size, and swelling analysis. 
In a nutshell, the aim of the present study was to develop a stable polymer-based film for buccal delivery of glimepiride and to investigate its performance. Additionally, the aim was also to characterize the film by new instrumental techniques along with the exploration of buccocompatibility and biophysics of buccoadhesion.

\section{MATERIALS}

Glimepiride was provided as a gift sample from Cipla Ltd. Goa, India. HPMC K 100 M (Methocel) was obtained as specimen sample from Dow Chemical International Pvt. Ltd. Mumbai, India. Carbopol (Ultrez-21) was purchased from Lubrizol Advanced Materials India Pvt. Ltd., Mumbai, India. Eudragit RL100 was supplied by Evonik Industries, Germany as a complimentary sample. Poloxamer (Pluronic F68), mucin (partially purified powder from porcine stomach; type III, with bound sialic acid of $0.5-1.5 \%$ ), and other chemicals and solvents were purchased from Sigma-Aldrich, USA. Freshly cut goat buccal mucosa was arranged from the local slaughter house, Lucknow, India.

\section{METHODS}

\section{Drug-Excipient Interactions}

Differential scanning calorimetry (DSC) and Fourier transform infrared spectroscopy (FTIR) analysis were performed to investigate physicochemical interactions of the drug and excipients. TA Differential Scanning Calorimeter fitted with a thermal analyst 2100 system (Universal V3.0G TA instruments, USA) was used to analyze the physical drugexcipients interaction. The ratio of drug-excipient mixture for interaction study was same to that of the amount of drug and excipients in the formulation (Table I). Sample was put in to pre-weighed sample pan, placed on the spacer insert, and sealed by a TA quick press. Sample pans were heated at a flow rate of $5^{\circ} \mathrm{C} / \mathrm{min}$; from 50 to $300^{\circ} \mathrm{C}$, and thermograms were obtained using thermal analyst software. Any chemical drugexcipients interaction between drug and polymers were investigated by FTIR (Shimadzu 8400S) spectroscopic analysis. Sample was blended with potassium bromide (1:100) and analyzed by FTIR spectrophotometer in the range of 4,000

Table I. Composition of Polymers Used in Formulation of Buccoadhesive Films

\begin{tabular}{lcccc}
\hline Film code/ingredients & Methocel & $\begin{array}{l}\text { Eudragit } \\
\text { RL 100 }\end{array}$ & $\begin{array}{l}\text { Ultrez } \\
21\end{array}$ & $\begin{array}{l}\text { Pluronic } \\
\text { F68 }\end{array}$ \\
\hline GM1 & 5 & 3 & 2 & - \\
GM2 & 5 & 3 & 2 & 2 \\
GM3 & 7.5 & 3 & 2 & - \\
GM4 & 7.5 & 3 & 2 & 2 \\
GM5 & 10 & 3 & 2 & 2 \\
GM6 & 10 & 3 & 4 & 2 \\
\hline
\end{tabular}

Solvent system: isopropanol and acetone (4:6). Method: solvent casting. Placebo of each formulation was prepared by same method. Plasticizer: propylene glycol. Penetration enhancer: dimethyl sulfoxide
$400 \mathrm{~cm}^{-1}$. FTIR spectra were obtained and studied for interaction between drug and polymers $(7,8)$.

\section{Formulation of Buccoadhesive Films}

Solvent casting technique was employed for the formulation of buccoadhesive films $(9,10)$. Composition of film formulations (GM1-GM6) is displayed in Table I. Accurately weighed quantity of glimepiride ( $2 \mathrm{mg}$ drug in $1 \mathrm{~cm}^{2}$ of film) and Eudragit RL100 were dissolved in 4:6 ratio of isopropanol and acetone ( $25 \mathrm{~mL}$ solvent mixture). Methocel and Ultrez-21 were prepared as $1 \%$ solution and stirred for $1 \mathrm{~h}$ to get a fine dispersion whereas the Eudragit-drug mixture was blended with the required quantity of Methocel and Ultrez-21 dispersion and was stirred (Eurostar overhead stirrer, IKA) for $1 \mathrm{~h}$ 30 min. Pluronic F68 was added to the mixture (GM2, GM4, GM5, and GM6) after 30 min of the stirring process of the drug-polymer mixture. A quantity of $0.1 \%$ of propylene glycol and $0.1 \%$ dimethyl sulfoxide were added at the final stage of mixing/stirring. The mixture was poured on Petri dishes and kept overnight at room temperature $\left(22 \pm 1^{\circ} \mathrm{C}\right)$. The prepared films were removed cautiously, cut in to $1-\mathrm{cm}^{2}$ size, and were stored in screw-capped glass container for further characterization. Placebo films (films without drug) were prepared by the same procedure.

\section{CHARACTERIZATION OF BUCCOADHESIVE FILMS}

\section{Conventional Characterization}

\section{Constriction Index, Surface pH, and Thickness}

Buccoadhesive film of $1 \mathrm{~cm}^{2}$ was cut (length wise) as strips in several pieces and the length of the cut pieces was measured $(1,11,12)$. Formula given below was used to calculate percent constriction.

Constriction $(\%)=\frac{L_{1}-L_{2}}{L_{1}} \times 100$ strip

Where $L_{1}=$ Initial length of film, $L_{2}=$ Final length of cut

For the determination of film's surface $\mathrm{pH}$, buccoadhesive film was placed on a Petri dish containing distilled water $(5 \mathrm{~mL})$ and kept in undisturbed condition for $15 \mathrm{~min}$ at room temperature $\left(22 \pm 1^{\circ} \mathrm{C}\right)$. $\mathrm{pH}$ was measured by placing the electrode of $\mathrm{pH}$ meter (Mettler Toledo AG) on the swelled surface of buccoadhesive film (10). For the measurement of thickness of films, random films were selected. Film was put in between two knobs of the digital screw gauge (Work Zone) and was screwed until it was freely movable. When it was fixed, the reading on the digital pan was noted. Thickness at upper, middle, and lower part (three different locations) of the each film was measured and the mean value was calculated.

\section{Swelling Behavior}

Buccoadhesive film was weighed, and the initial weight was denoted as $W_{1}$. Film was put in a Petri dish containing 
$5 \mathrm{~mL}$ of phosphate buffer ( $\mathrm{pH} 6.8)$ at room temperature $(22 \pm$ $1^{\circ} \mathrm{C}$ ) in an undisturbed condition. The film was removed carefully at each hour for $4 \mathrm{~h}$ from the Petri dish and excess of solvent was soaked by a filter paper. The swelled film was weighed and weight was designated as $W_{2}$. Swelling index of films was calculated by using the following formula (13).

$\operatorname{SI}(\%)=\frac{\left[W_{2}-W_{1}\right]}{W_{1}} \times 100$

Where, SI = swelling index, $W_{1}=$ initial weight of buccoadhesive film, $W_{2}=$ weight of swelled buccoadhesive film

\section{Drug Content}

Films were crushed in to small pieces and dissolved in $100 \mathrm{~mL} 0.1 \mathrm{~N} \mathrm{NaOH}$ solution. The resulting solution was filtered through a $0.45-\mu \mathrm{m}$ syringe filter, and a $15-\mu \mathrm{g} / \mathrm{mL}$ sample was prepared from the stock solution. The prepared sample was scanned at $227 \mathrm{~nm}\left(\lambda_{\max }\right)$ and concentration of drug was determined using UV-VIS Spectrophotometer (SpectraMax, Molecular Devices, USA) (9).

\section{Folding Endurance}

The method described by Avachat et al. was followed for the folding endurance examination (10). Buccoadhesive film was folded at a same place for repeated times manually. The process was continued till the film was broken/torn. The number of times the film could be folded at the same place without breaking was denoted as the folding endurance. The whole experiment was performed by a single person (trained research scholar) in order to avoid operational error.

\section{In Vitro Residence Time}

United States Pharmacopeia (USP) disintegration apparatus was modified as reported by Nafee et al., for the evaluation of in vitro residence time. Briefly, modified USP disintegration apparatus was filled with $800 \mathrm{~mL}$ phosphate buffer solution ( $\mathrm{pH}$ 6.8) and maintained at $37 \pm 2{ }^{\circ} \mathrm{C}$. The buccoadhesive film was fixed to the goat buccal mucosa on glass slab attached to the apparatus. The experiment was performed, and time required for complete detachment of the film from the mucosa surface was recorded as residence time $(13,14)$.

\section{Contemporary Characterization}

Contemporary characterization (film strength, buccoadhesive strength, and tensile strength) were carried out by CT3 texture analyzer (Brookfield Engineering Lab, Inc., USA). The test specification and some of the representative photographs of tests are given in the supplementary materials. The data obtained in the experiments were analyzed by CT3 Texture Pro software (Brookfield Engineering Lab, Inc.).

\section{Film Strength}

Selected film was placed on the support fixture (TA-BT KIT), and the CT3 texture analyzer was aligned with the fixture base. Cylindrical pointed probe (TA 42, $3 \mathrm{~mm}$ ) was selected to check the film strength, and test specification was programmed (supplementary materials, Table S-1). Compression test was commenced at a pre-specified velocity and force as well as work done to make break/wear-tear on the film was measured (15).

\section{Buccoadhesive Strength}

The upper probe of dual extrusion (TA-DEC) cell was glued with goat buccal mucosa. Film was fixed on the metal base plate. The upper probe was pressed on the buccoadhesive film for 5 min (pre-contact time). After precontact time, the upper probe was moved upward at a prespecified velocity (supplementary materials Table S-1). Force and work done to completely separate both film and buccal mucosa was measured with the help of Texture Pro software (15).

\section{Tensile Strength}

The TA-DGA probe was employed for the tensile strength characterization. The buccoadhesive film was fixed with this probe between the rubber inserts. The experiment was commenced with the pre-specified time/velocity protocol (supplementary materials Table S-1). Force/work done to disrupt/tear the film was measured with the help of Texture Pro software (15).

\section{Zeta Potential $(\zeta)$ and Particle Size Measurement}

The polymeric film was homogenized with small volume of distilled water and allowed to stand for $6 \mathrm{~h}$. Meanwhile, mucin was dispersed in distilled water to make stock solutions of $1 \% w / w$. Equal volume of both dispersions were mixed and diluted with distilled water. The zeta potential of the mixture was measured using Zetasizer NanoZS (Malvern, UK) at $22 \pm$ $1{ }^{\circ} \mathrm{C}$. The mean particle size and particle distribution (polydispersity index; PDI) were measured by the same instrument (16).

\section{In Vitro Drug Release}

In vitro drug release of buccoadhesive films was carried out with USP 5 (paddle over disc, $65 \mathrm{~mm}$ ) dissolution apparatus (Electrolab India Pvt. Ltd.) (17). Dissolution media phosphate buffer $(\mathrm{pH} 6.8)$ with $0.1 \%$ tween was taken in the vessels and the disc was placed properly. The experimental set-up was maintained at $37 \pm 2^{\circ} \mathrm{C}$ and $50 \pm 2 \mathrm{RPM}$. The selected film was placed below the disc and dissolution test was started, aliquots of $5 \mathrm{~mL}$ were withdrawn at pre-specified time intervals for $12 \mathrm{~h}$. The aliquots were filtered through syringe filter $(0.45 \mu)$, absorbance was taken at $227 \mathrm{~nm}$ by UV-VIS spectrophotometer, and quantity of drug released to the dissolution medium was calculated. Measured amount $(5 \mathrm{~mL})$ of fresh pre-warmed dissolution media was added to the 
dissolution vessel to maintain sink condition. Experiment was conducted in triplicates $(n=3)$ and mean, SEM were calculated.

\section{Ex Vivo Drug Permeation}

Ex vivo drug permeation was evaluated as described by Cavallari et al. (9) with slight modification. Briefly, the donor and receptor compartment of Franz diffusion cell was filled with 5 and $45 \mathrm{~mL}$ phosphate buffer with $0.1 \%$ tween $(\mathrm{pH} \mathrm{6.8)}$ respectively as dissolution media. A $2-\mathrm{cm}^{2}$ (area) size buccal mucosa of goat was carefully fixed on the diffusion cell sandwiched between the donor and receptor compartment, and then the selected film was fixed on the goat mucosal membrane. Experimental conditions were maintained at $37 \pm$ $2{ }^{\circ} \mathrm{C}$ and $50 \pm 5$ RPM with the help of a magnetic stirrer cum hot plate (Ika, Germany). At pre-specified time intervals, aliquots of $1 \mathrm{~mL}$ were collected for $12 \mathrm{~h}$, and processed as mentioned in in vitro drug release study. Percent drug permeated through the buccal mucosa was calculated. Experiment was conducted in triplicates $(n=3)$, and mean, SEM were calculated.

\section{In Vitro Buccocompatibility}

Agar diffusion assay was employed to investigate growth inhibitory effect of films on probiotic microorganisms (Lactobacillus acidophilus, Bifidobacterium infantis, and Lactobacillus rhamnosus) present in buccal microflora (18). Probiotic bacterial suspension was spread on the agar plates containing media. An amount of $10 \mu \mathrm{L}$ of sample (drug loaded buccoadhesive film suspension) was added to the sterile paper disc ( $5 \mathrm{~mm}$ diameter, Whatman cellulose filter papers), and it was placed on the seeded plates. The same procedure was applied for placebo film, and plates were incubated at $37^{\circ} \mathrm{C}$ for $36 \mathrm{~h}$ under anaerobic conditions. After incubation, the diameter of growth inhibition zone were measured and noted down for interpretation.

\section{Electron Microscopy}

Scanning electron microscopy of selected buccoadhesive films were performed to study the surface morphology (19). Samples were prepared by fixing films on stubs and coated with gold palladium with the help of a gold sputter module in a high vacuum evaporator. The prepared stubs were analyzed with LEO 420 (LEO Electron Microscopy Ltd., England) using secondary electron imaging. Various sights of film at different magnification were viewed and recorded for interpretation.

\section{Stability Studies}

Selected buccoadhesive films were subjected to stability analysis. Individual film was wrapped in aluminum foil and set aside in an air-tight glass container at $4 \pm 0.5$ and $22 \pm 1^{\circ} \mathrm{C}$ for 6 months. At pre-determined time intervals (1, 3, and 6 month), these films were evaluated for all characterization parameters (10).

\section{Statistical Analysis}

All values of the characterization parameters were presented as mean \pm SEM. In order to investigate the statistical significance difference (if any) in the characterized parameters, one-way ANOVA was employed by using the GraphPad Prism 5 Statistical Software (GraphPad Prism Version 5.01).

\section{RESULTS AND DISCUSSION}

\section{Drug-Excipient Compatibility}

Table II exhibits the FTIR and DSC results of glimepiride and buccoadhesive films. A very minor shift in the characteristic peaks of functional groups of glimepiride (pure drug) was observed in comparison to the standard FTIR spectrum of glimepiride. There was no significant shift in the characteristic peaks of functional groups of glimepiride in the buccoadhesive film formulations in comparison to the FTIR spectrum of glimepiride. These results suggested that there was no physical incompatibility of glimepiride and excipients/polymers. Ammar et al. and Park et al. are also in agreement with the compatibility of glimepiride with polymers and excipients such as HPMC, Poloxamer, Carbopol, etc. (20,21). Figure 1 displays the FTIR spectra of (A) glimepiride and the formulated (B) buccoadhesive film.

In the DSC thermogram of glimepiride (pure drug), a sharp peak at $205.50^{\circ} \mathrm{C}$ was noted that corresponds to the melting point peak of glimepiride (21). DSC thermogram of buccoadhesive film formulation displayed a peak at $65.35^{\circ} \mathrm{C}$ which is the melting point peak of Poloxamer (Pluronic F68), while the corresponding melting point peak of glimepiride was absent. Such results might be interpreted to the unavailability/ degradation of glimepiride in the polymeric matrix or any significant interactions among the drug and polymers/excipients. Another possibility of such phenomena might be the dissolution of glimepiride in the melted Pluronic F68 and consequently conversion of solid/crystalline glimepiride to liquid (solution state) resulting into deletion of melting point peak of glimepiride. Table II shows the DSC parameters, and subpanels a and b of Fig. 2 illustrate the DSC thermograms of glimepiride and buccoadhesive film, respectively. Cides et al. have also reported similar phenomena for

Table II. FTIR and DSC Results of Glimepiride and Buccoadhesive Films

\begin{tabular}{|c|c|c|c|}
\hline \multicolumn{2}{|l|}{ Category } & $\begin{array}{l}\text { Glimepiride } \\
\text { pure drug }\end{array}$ & $\begin{array}{l}\text { Buccoadhesive } \\
\text { film }\end{array}$ \\
\hline \multicolumn{4}{|c|}{ FTIR characteristic peaks $\left(\mathrm{cm}^{-1}\right)$} \\
\hline \multicolumn{2}{|l|}{$\mathrm{N}-\mathrm{H}$ stretching } & $3,341.56$ & $3,342.05$ \\
\hline \multicolumn{2}{|l|}{$\mathrm{N}-\mathrm{H}$ bending } & 1,670 & 1,673 \\
\hline \multicolumn{2}{|l|}{$\mathrm{C}=\mathrm{O}$ stretching } & $1,712.42$ & $1,708.38$ \\
\hline \multicolumn{2}{|l|}{ O-H stretching } & $2,865.82$ & $2,868.46$ \\
\hline \multicolumn{2}{|l|}{$\mathrm{C}-\mathrm{N}$ stretching } & 1,170 & 1,168 \\
\hline \multicolumn{2}{|c|}{ Sulfonamide stretching } & 1,345 & 1,345 \\
\hline \multicolumn{4}{|l|}{ DSC parameters } \\
\hline \multirow[t]{3}{*}{ Melting point $\left({ }^{\circ} \mathrm{C}\right)$} & Onset & 202.65 & 61.66 \\
\hline & Peak & 205.50 & 65.35 \\
\hline & Endset & 207.45 & 68.46 \\
\hline
\end{tabular}




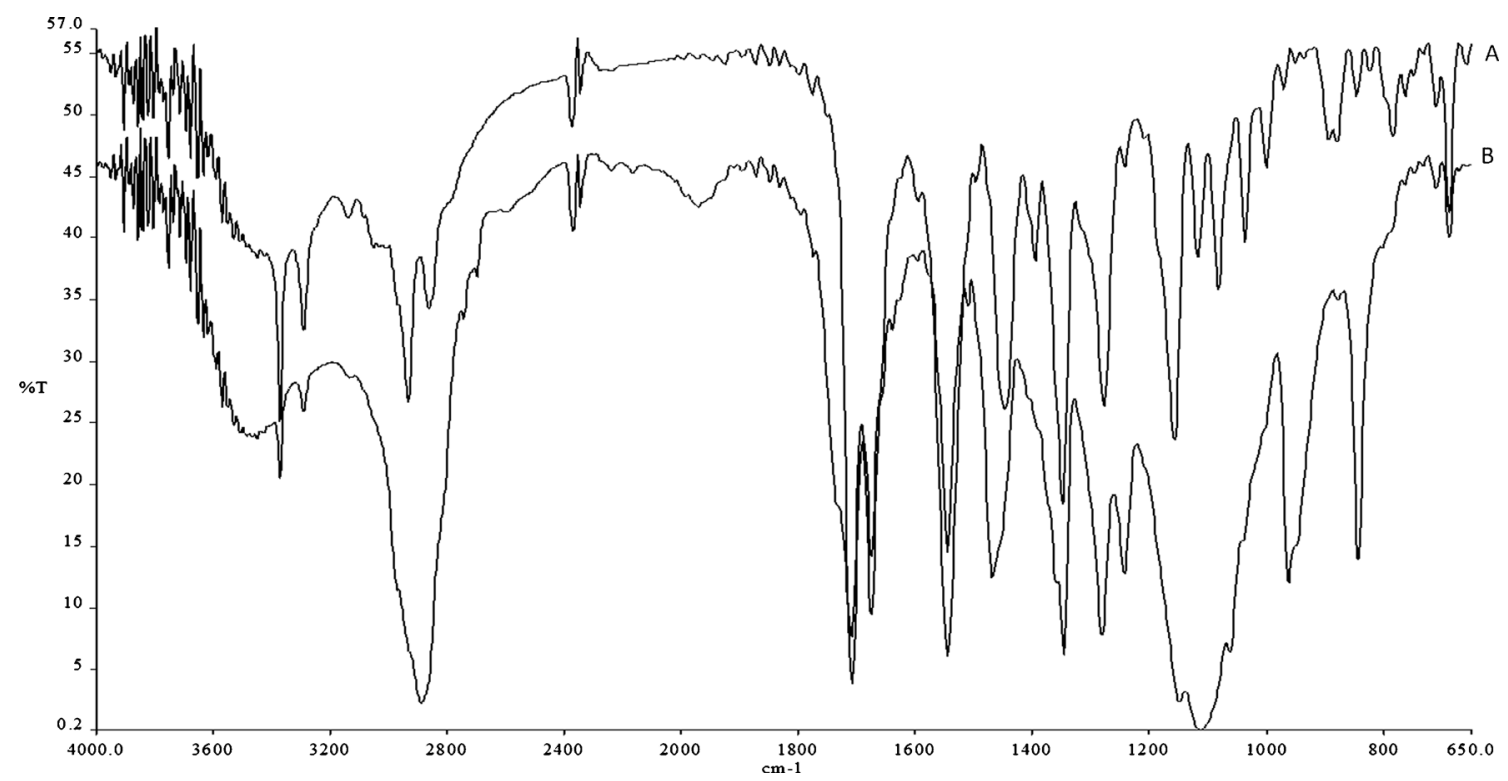

Fig. 1. FTIR spectra of glimepiride (A) and the formulated (B) buccoadhesive film

glimepiride, while many authors have reported such phenomena for other drug molecules (22-24).

\section{Formulation and Characterization of Buccoadhesive Films}

Table I exhibits the compositions of six formulations (GM1 to GM6) with various polymer combinations. Methocel (HPMC) was employed as the central drug release rate controlling polymer, and its concentration was progressively increased in the film formulations, whereas concentration of other polymers viz. Eudragit (rate controlling) and Ultrez-21 (Carbopol; buccoadhesive polymer) was kept constant in all formulations except GM6. Pluronic F68 (Poloxamer) was incorporated in the film formulations GM2, GM4, GM5, and GM6 as a functional polymer whose role was to impart additive effect on the buccoadhesion by manipulating the charge in presence of mucin. A quantity of $0.1 \%$ of propylene glycol and $0.1 \%$ dimethyl sulfoxide was added to the films as plasticizer and penetration enhancer, respectively. Figure 3 a displays one of the representative buccoadhesive films.

Results of the conventional characterization parameters are shown in Table III. Constriction index was determined for films and found to be in the range of 0 to $2.8 \pm 0.24 \%$. Zero percent constriction indexes imply $100 \%$ flatness and film formulation GM4 and GM6 exhibited 100\% flatness. A perfectly flat film assures adequate contact to the mucosal surface and consequently uniform absorption of the drug. The surface $\mathrm{pH}$ of the films were found to be $5.30 \pm 0.86$ to $6.53 \pm 0.64$, which ensured compatibility with the buccal region $(\mathrm{pH} ; 6.5-$ 6.8). The thicknesses of the films were in micrometers and in the range of $700 \pm 30$ to $770 \pm 20 \mu \mathrm{m}$. The films are sufficiently thin which can be easily accommodated in the buccal cavity. An increase in the film thickness in the ascending order of formulations, i.e., GM1-GM6 was attributed to the increase in the concentration of polymer concentration (Table I). Avachat et al., Abruzzo et al., and Meher et al. have also reported similar characteristics of various buccal films developed with different polymers $(10,18,25)$. A well-planned swelling study was performed for a period of $4 \mathrm{~h}$, where it was observed that with the increase in Methocel concentration, the swelling index was increased in a nonlinear fashion. GM1 showed lowest $(22.30 \pm 2.6 \%)$ and GM6 exhibited highest $(30.08 \pm$ $3.24 \%$ ) swelling after $3 \mathrm{~h}$ and remained unchanged up to next $1 \mathrm{~h}$. Higher water uptake of GM6 was due to the high concentration of hydrophilic polymer Ultrez-21 in the film facilitating high swelling as well as water absorption. It has been observed that polymeric matrix containing hydrophilic polymers (HPMC, Carbopol etc.) leads to erosion of film upon hydration. This phenomenon is due to the breaking of polymer chain after penetration of water into the matrix. Jug et al. have demonstrated such erosion behavior of polymeric matrix in their investigation (26). In the present study, any erosion of film was not observed except in GM6. It was hypothesized that presence of Eudragit (hydrophobic polymer) might have interfered with the erosion behavior and at the same time Pluronic F68 (Poloxamer) might also have contributed additive effect in maintaining the viscoelastic characteristics of film. Hence, no erosion has been seen in GM1-GM5 films, whereas a minor erosion behavior of GM6 was observed in swelling and dissolution/permeation studies. The higher concentration of Ultrez-21 and Methocel in GM6 caused an increase in the hydrophilic nature of film and overcome the counter effect of Eudragit and Pluronic F68, leading to erosion. Drug content of all the films were determined and found to be in the range of $96.00 \pm 2.18$ to $99.00 \pm 1.08 \%$.

Folding endurance was found to be in between $84 \pm 18$ and $100 \pm 18$ times. This result exhibited a good mechanical strength of the films. Many researchers used and reported folding endurance method in film/patch formulations (2729). However, such conventional method does not exhibit high reproducibility and should be replaced with more precise and sophisticated technical methods. Adherence of film at the place of administration is a very crucial aspect in buccal delivery. It all depends on the mucoadhesive characteristics of the film and also on the swelling/erosion behavior. All buccoadhesive films displayed sufficient adhesion in stress (mechanical agitation) condition and was observed to be $88.2 \pm 8.67$ to $100 \pm 8 \mathrm{~min}$. After these time durations, films were completely detached from the glass slab. These results indicate that in partially stationary condition (buccal 
a

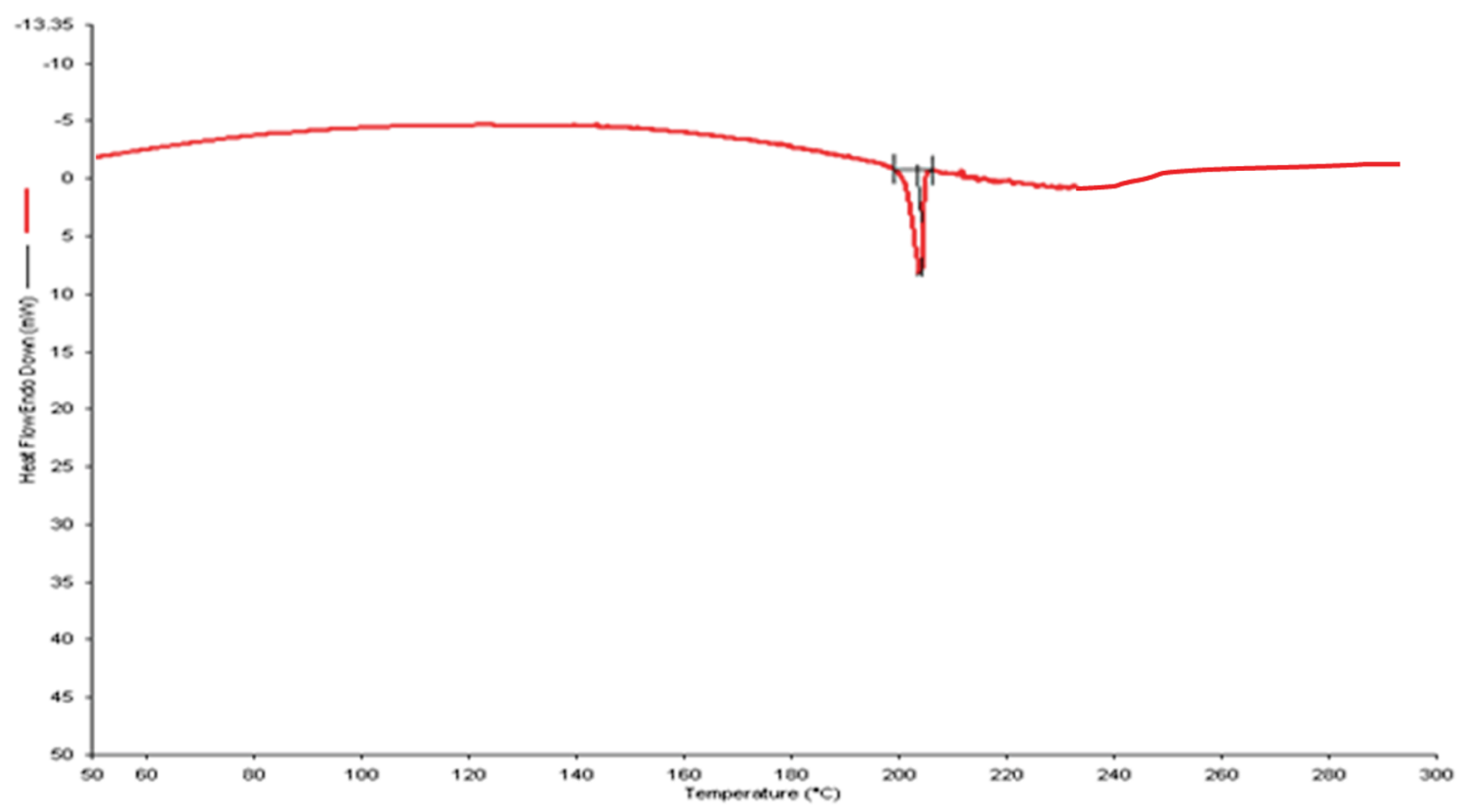

b

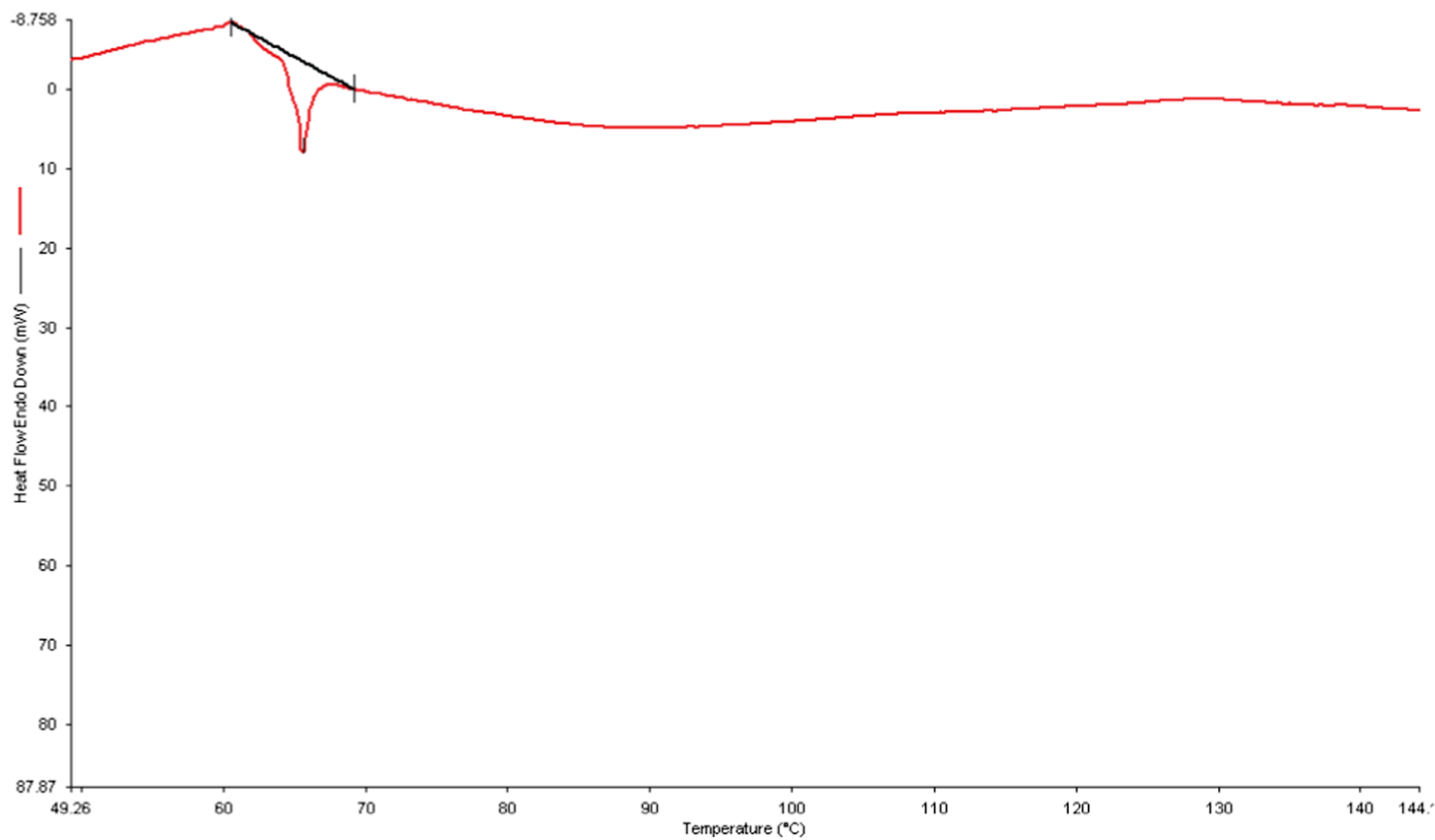

Fig. 2. DSC thermogram of glimepiride (a) and developed buccoadhesive film (b)

environment), these films might show adequate adherence. Till now, the conventional parameters of film characterization were discussed, which are routinely performed for films and in the further section the contemporary parameters of film characterization will be discussed.

Buccoadhesive strength is the force/work required for detaching any film/patch (buccoadhesive formulation) from buccal mucosal surface and depends on the bond strength responsible for buccoadhesion (30). New techniques of buccoadhesive strength measurement were employed using CT3 Texture Analyzer with Texture Pro CT V1.3 Build 15 Software. More accurate and precise results were recorded by this technique and are depicted in Table IV. Ulterz-21 (Carbopol) was responsible for buccoadhesion, and Methocel exhibited additive effect on buccoadhesion. Increase in Methocel concentration resulted into increase in buccoadhesion which is attributed to the increase in hydration (high swelling, Table III) as well as flexibility of the polymeric matrix. Highest buccoadhesion (force, work done) was recorded for GM6, i.e., $32.86 \pm 1.50 \mathrm{~g}$ and $3.82 \pm 0.24 \mathrm{~mJ}$ (Table IV). Lowest buccoadhesion was shown by GM1 $(24.6 \pm 2.00 \mathrm{~g}$ and $2.24 \pm 0.82 \mathrm{~mJ})$ which might be due to less concentration of Ultrez-21 as well as absence of Pluronic. 

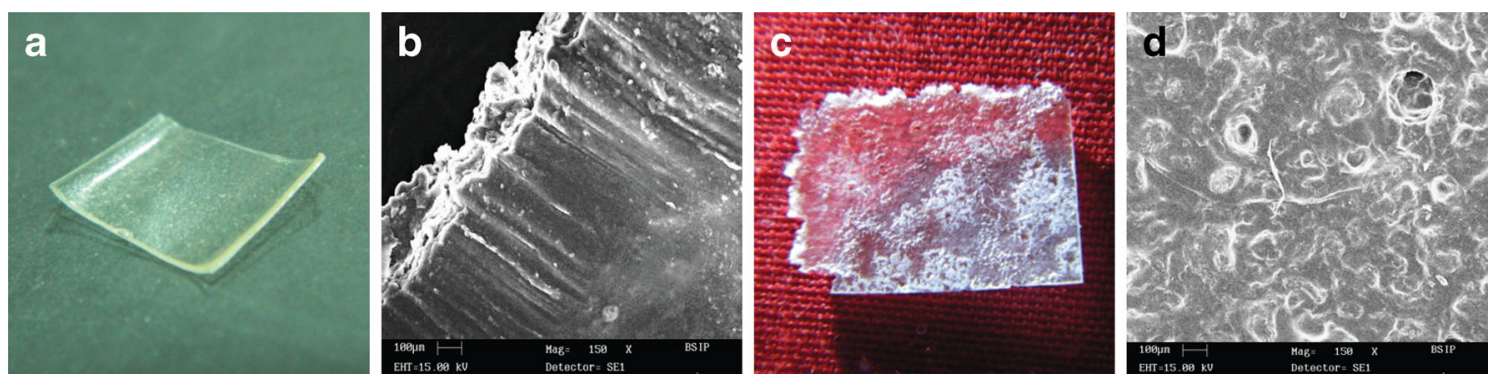

Fig. 3. Photographs of buccoadhesive film and SEM photomicrograph of buccoadhesive film before and after dissolution studies. a Photograph of buccoadhesive film. b SEM micrograph of buccoadhesive film before dissolution. $\mathbf{c}$ Photograph of buccoadhesive film after $12 \mathrm{~h}$ of dissolution studies. d SEM micrograph of buccoadhesive film after $12 \mathrm{~h}$ of dissolution studies

Film strength, which is a reflection of the mechanical strength of the film, is usually measured by folding endurance/resilience test. This method has been used by many investigators but highly lacks in terms of reproducibility $(10,18)$. Therefore, a new and simple set-up for film strength evaluation was developed using CT3 Texture Analyzer with Texture Pro CT V1.3 Build 15 Software (supplementary material). Film strength was determined to be in the range of $280.88 \pm 8.5$ to $352 \pm 12.56 \mathrm{~g}$ (Table IV). Higher concentration of polymers in GM6 was found to give high mechanical strength to the films; however, sufficient strength was shown by other film formulations. Tensile strength gives the flexibility of the film a measure for mechanical strength. The tensile strength of the developed films were found to be $250 \pm 8.26 \mathrm{~g}$ $(15.80 \pm 0.60 \mathrm{~mJ})$ to $270 \pm 8.54 \mathrm{~g}(20.00 \pm 2.12 \mathrm{~mJ})$ (Table IV) Presence of Poloxamer in the films (GM4, GM5, and GM6) in combination with Ultrez-21 and Methocel has remarkably increased the tensile strength of the film. Since mucoadhesive preparations are included in the European Pharmacopoeia 7.4 (2012), it is presumed that precise and reproducible methods will be established soon and the method reported in this investigation may be an important contribution in this regard.

\section{Biophysics of Buccoadhesion}

Biophysical phenomena describe the insight mechanism of buccoadhesion and correlate the physical attributes viz. zeta potential $(\zeta)$, particle size, and swelling of polymeric matrixmucin mixture with buccoadhesion. The buccoadhesive phenomenon has been explained by five classical theories viz. wetting, adsorption, diffusion, electrical, and fracture where the adhesive material interact with substrate tissue (31). In the present investigation, increase in the swelling of polymeric matrix increased the buccoadhesive strength (Tables III and IV). Higher quantity of Methocel and presence of Pluronic facilitated the wetting phenomena. GM4, GM5, and GM6 exhibited higher swelling which was required to develop the mucoadhesive network as well as adhesive sites for bond formation and also created pores for diffusion of polymer chains to mobilize the inter-penetration. A time-dependent buccoadhesion study was carried out for $8 \mathrm{~h}$ and it was observed that buccoadhesive strength increased initially for $4 \mathrm{~h}$ and then decreased (Fig. 4). These results are in accordance to the wetting and swelling phenomenon in buccoadhesion.

In order to investigate the impact of electrical forces (electrical theory) on buccoadhesion, measurement of zeta potential was employed. The electrical theory is based on hypothesis that when the polymers come in contact with the mucosal surface, electron transfer occurs to balance Fermi levels, resulting into development of an electrical charge (double layer) at polymer-mucin interface. Buccoadhesive force is generated due to attraction forces across this electrical double layer. Figure 5 exhibits change in zeta potential of mucin in combination with various films. Mucin exhibited a zeta potential of $-22.46 \pm 7.34 \mathrm{mV}$ and it was increased with the polymeric matrix dispersion (Fig. 5). This might have happened due to increased number of negatively charged carboxyl groups in the mixtures causing an electrostatic repulsion between the negative charges of carboxyl groups and sialic acid in mucin

Table III. Conventional Parameters of Buccoadhesive Film Characterization

\begin{tabular}{|c|c|c|c|c|c|c|}
\hline \multirow[t]{2}{*}{ Evaluation parameters } & \multicolumn{6}{|c|}{ Formulation code } \\
\hline & GM1 & GM2 & GM3 & GM4 & GM5 & GM6 \\
\hline Constriction index ${ }^{\mathrm{a}}(\%)$ & $2.8 \pm 0.24$ & $1.2 \pm 0.44$ & $1.4 \pm 0.14$ & 0 & $2.5 \pm 0.35$ & 0 \\
\hline Surface pH & $5.30 \pm 0.86$ & $6.53 \pm 0.64$ & $5.80 \pm 0.26$ & $6.45 \pm 0.48$ & $5.88 \pm 0.45$ & $6.15 \pm 0.28$ \\
\hline Film thickness $(\mu \mathrm{m})$ & $700 \pm 30$ & $720 \pm 25$ & $735 \pm 40$ & $740 \pm 30$ & $770 \pm 20$ & $750 \pm 30$ \\
\hline Swelling index ${ }^{\mathrm{b}}(\%)$ & $22.30 \pm 2.6$ & $22.98 \pm 3.45$ & $24.66 \pm 3.26$ & $26.28 \pm 2.68$ & $26.88 \pm 2.64$ & $30.08 \pm 3.24$ \\
\hline Drug content (\%) & $96.00 \pm 3.54$ & $96.46 \pm 2.90$ & $98.44 \pm 1.08$ & $97.30 \pm 2.08$ & $99.00 \pm 1.08$ & $96.00 \pm 2.18$ \\
\hline Folding endurance (times) & $88 \pm 12$ & $84 \pm 18$ & $90 \pm 15$ & $100 \pm 18$ & $100 \pm 16$ & $98 \pm 14$ \\
\hline In vitro residence time ( $\mathrm{min})$ & $98.4 \pm 4.32$ & $88.2 \pm 8.67$ & $96.4 \pm 6.60$ & $90 \pm 5.00$ & $96.2 \pm 4.00$ & $100 \pm 8.00$ \\
\hline
\end{tabular}

Mean \pm SEM, $n=3$

${ }^{a}$ Zero percent constriction implies $100 \%$ flatness

${ }^{b}$ Swelling index was determined after $4 \mathrm{~h}$ of exposure of the film in phosphate buffer medium 
Table IV. Contemporary Parameters of Buccoadhesive Film Characterization

\begin{tabular}{|c|c|c|c|c|c|c|}
\hline \multirow[t]{2}{*}{ Evaluation parameters } & \multicolumn{6}{|c|}{ Formulation code } \\
\hline & GM1 & GM2 & GM3 & GM4 & GM5 & GM6 \\
\hline \multicolumn{7}{|l|}{ Film buccoadhesive strength ${ }^{\mathrm{a}}$} \\
\hline Buccoadhesive strength (g) & $24.6 \pm 2.00$ & $26.6 \pm 1.42$ & $25.18 \pm 2.00$ & $28.8 \pm 1.37$ & $30.44 \pm 1.84$ & $32.86 \pm 1.50$ \\
\hline Work done (mJ) & $2.24 \pm 0.82$ & $2.80 \pm 0.62$ & $2.08 \pm 0.34$ & $3.04 \pm 0.32$ & $3.22 \pm 0.54$ & $3.82 \pm 0.24$ \\
\hline \multicolumn{7}{|l|}{ Film strength $^{\mathrm{b}}$} \\
\hline Film strength (g) & $300 \pm 10.56$ & $280.88 \pm 8.5$ & $325 \pm 10$ & $320 \pm 8.5$ & $340 \pm 10$ & $352 \pm 12.56$ \\
\hline Work done (mJ) & $28.00 \pm 1.68$ & $22.80 \pm 2.16$ & $30.90 \pm 2.45$ & $28.98 \pm 2.00$ & $32.12 \pm 1.82$ & $33.20 \pm 1.52$ \\
\hline \multicolumn{7}{|l|}{ Tensile strength ${ }^{\mathrm{c}}$} \\
\hline Tensile strength $(\mathrm{g})$ & $250 \pm 8.26$ & $245 \pm 9.50$ & $262 \pm 8.26$ & $260 \pm 6.88$ & $275 \pm 7.00$ & $270 \pm 8.54$ \\
\hline Work done $(\mathrm{mJ})$ & $15.80 \pm 0.60$ & $14.00 \pm 1.20$ & $17.00 \pm 1.00$ & $18.00 \pm 0.44$ & $22.00 \pm 1.56$ & $20.00 \pm 2.12$ \\
\hline
\end{tabular}

Mean \pm SEM, $n=3$

${ }^{a}$ Dual extrusion cell (probe-TA-DEC); fixture base table (TA-BT KIT); compression mode

${ }^{b}$ Cylindrical probe-3 mm (probe-TA 42); film support fixture (TA-FSF); compression mode

${ }^{c}$ Dual grip set-up (probe-TA-DGA); tension mode

(32). GM6 exhibited a higher negative value of zeta potential which can be evidently correlated to the higher concentration of Ultrez-21 in GM6 (Table I). Figure 6a shows a direct correlation between zeta potential and buccoadhesion.

In the next step, the impact of particle size of mucin-film mixture on buccoadhesive strength was investigated. Figure $6 \mathrm{~b}$ shows the correlation between the particle size and buccoadhesion. It was observed that lower particle size facilitated higher buccoadhesion which might be due to the intimate contact of mucin with the polymeric matrix surface. The presence of Pluronic F68 might have contributed to viscoelastic behavior of polymer-mucin matrix leading to adequate interaction via hydrogen bonds and other interactions (16). To investigate any correlation between the particle size and zeta potential of mucin-film mixture, a plot was drawn (Fig. 5). Results demonstrated that there was no such correlation. Subsequently, charge and the particle size were found to exist as independent variables in biophysical aspects of buccoadhesion. Based on the above findings, it can be stated that the theories of buccoadhesion viz. adsorption, electrical, and wetting are responsible in the biophysics of buccoadhesion.

\section{Drug Release and Permeation}

Figure $7 \mathrm{a}, \mathrm{b}$ exhibits the in vitro and ex vivo zeroorder release/permeation pattern of the buccoadhesive films. Table V shows the " $R$ " and " $n$ " values of different drug release/permeation kinetic models. The films GM1 and GM2 exhibited $96 \pm 4$ and $95 \pm 5 \%$ in vitro drug release in $8 \mathrm{~h}$, while other films (GM3-GM6) could extend the release up to $12 \mathrm{~h}$. GM4 exhibited highest $(98 \pm 5 \%)$ drug release in vitro in $12 \mathrm{~h}$ and there was a significant difference $(P<0.05)$ in the in vitro drug release of films. Various drug release kinetic models were fitted in the release data and it was revealed that films followed zero-order kinetic and diffusion (Fickian) mechanism (Table V). Similarly, the ex vivo drug permeation through the goat buccal mucosa exhibited zero-order permeation kinetic and diffusion (Fickian) controlled drug permeation mechanism. The highest drug permeation was found to be $96 \pm 4 \%$ in $12 \mathrm{~h}$ for GM1 whereas GM4 exhibited $85 \pm 4 \%$ in the same time. A significant difference $(P<0.05)$ was observed between the permeation characteristics of films.

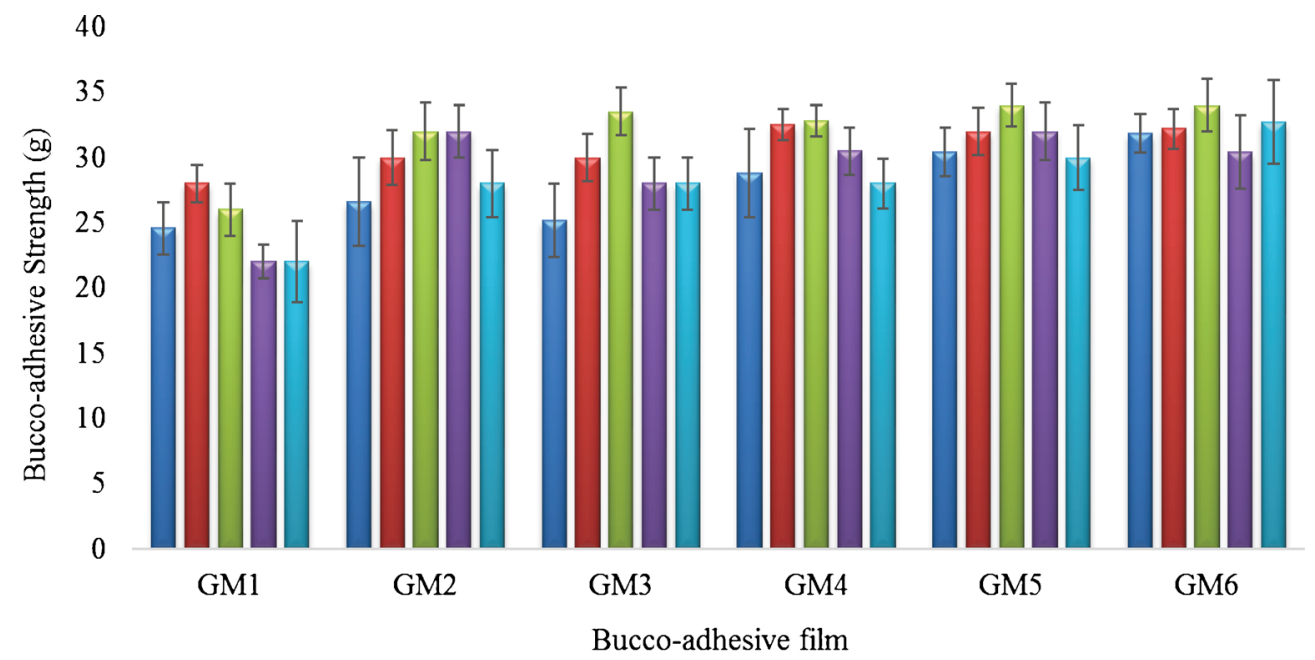

$\square 1 \mathrm{~h} \square 2 \mathrm{~h} \square 4 \mathrm{~h} \square 6 \mathrm{~h} \square 8 \mathrm{~h}$

Fig. 4. Buccoadhesive strength of films at different time intervals up to $8 \mathrm{~h}$ 


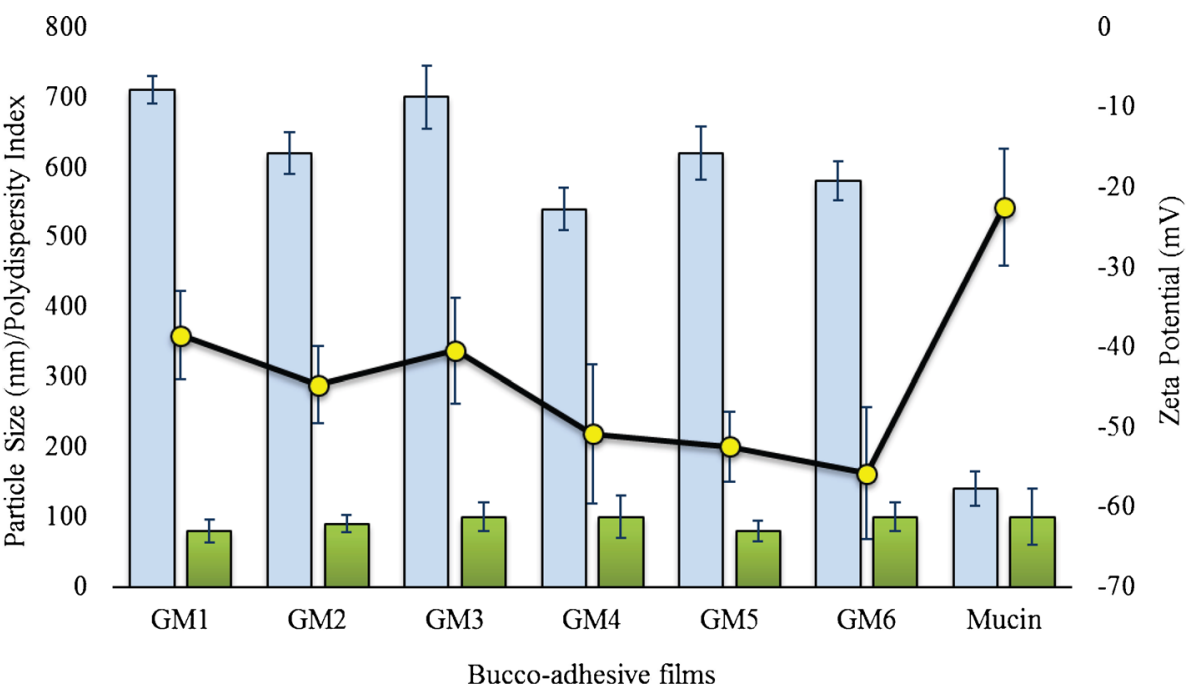

$\varpi$ Particle Size $\square P^{*} 100 \quad-$-Zeta Potential

Fig. 5. Particle size, polydispersity index, and zeta potential of buccoadhesive films (polydispersity index data is multiplied with 100 to make it visible on the graph)

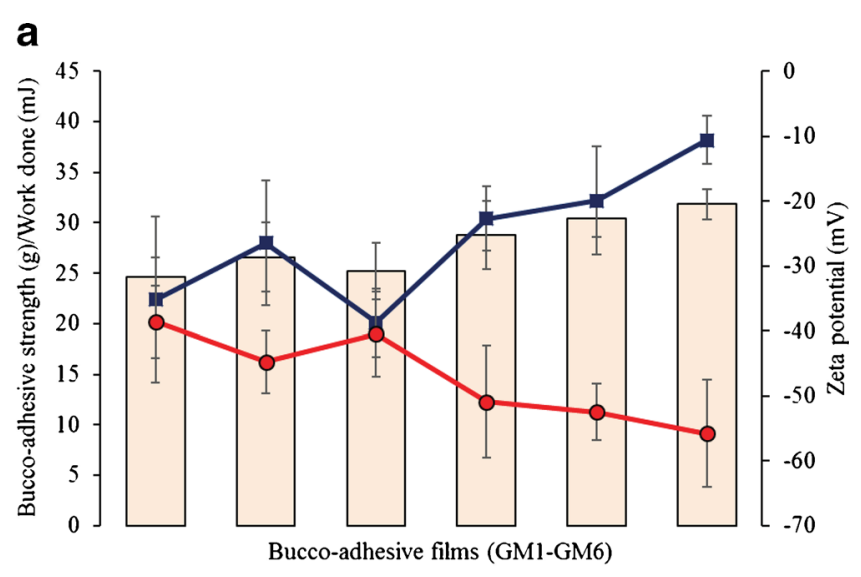

$\square$ Bucco-adhesive strength $(\mathrm{g}) \rightarrow$-Work done $(\mathrm{mJ})-$-Zeta Potential

b

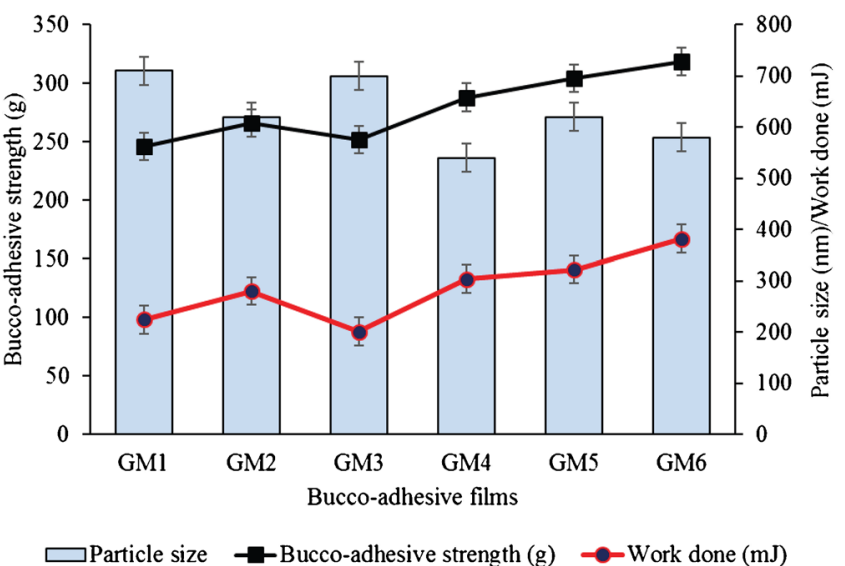

Fig. 6. Comparative plot showing relation of zeta potential, particle size, and buccoadhesion (values are increased up to 100 times to maintain the scale). a Zeta potential and buccoadhesive strength and work done in buccoadhesion. b Particle size and buccoadhesive strength and work done in buccoadhesion
Comparatively low drug permeation in ex vivo studies than in vitro drug release is attributed to the complexity of goat buccal mucosa. Such phenomena are demonstrated by Avachat et al. and Muzib et al. (10,29).

In both the studies, a significant $(p<0.05)$ difference was observed in the release/permeation of the films. Variation in the drug release/permeation was attributed to the higher concentration of rate controlling polymer (Methocel) which caused more hydration and swelling of buccoadhesive film. This phenomenon also occurs in the development of a hydrogel layer (ultrez-21 in basic $\mathrm{pH}$ ) in the vicinity of dispersed drug molecule. Development of the thick hydrogel layer might have resulted in increasing the drug release/diffusion path length, bring about delayed dissolution as well as diffusion of glimepiride. Maderuelo et al. have demonstrated such behavior in drug release from hydrophilic matrices $(33,34)$.

\section{Buccocompatibility}

Few studies are available in literature regarding the compatibility issues of buccoadhesive films in the buccal environment (18). In our present work, buccoadhesive films were investigated for any incompatibility with the buccal probiotic microorganisms viz. L. acidophilus, B. infantis, and L. rhamnosus by agar diffusion method. Results demonstrated a very weak bacteriostatic effect on these microorganisms by GM1 and GM2 films. Buccoadhesive films GM2, GM4, GM5, and GM6 exhibited bactericidal effect with net zone of growth inhibition in the range of $4 \pm 1$ to $2 \pm 1 \mathrm{~mm}$ (supplementary Table S-2). Placebo of these films also exhibited $2 \pm 1$ to $1 \mathrm{~mm}$ net zone of growth inhibition, whereas placebo of GM1 and GM3 did not show any inhibitory effect (supplementary Table S-2). Such findings suggested that the film formulations did not possess any incompatibility to the buccal microflora. The minor inhibitory effect of some films might be due to the antimicrobial action of Pluronic which is in agreement with the previously reported work $(35,36)$. 


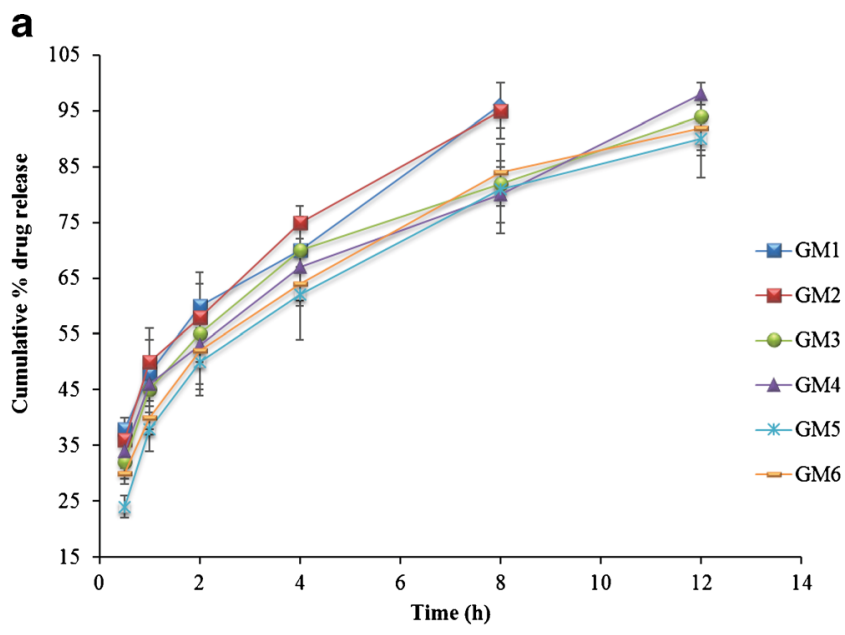

b

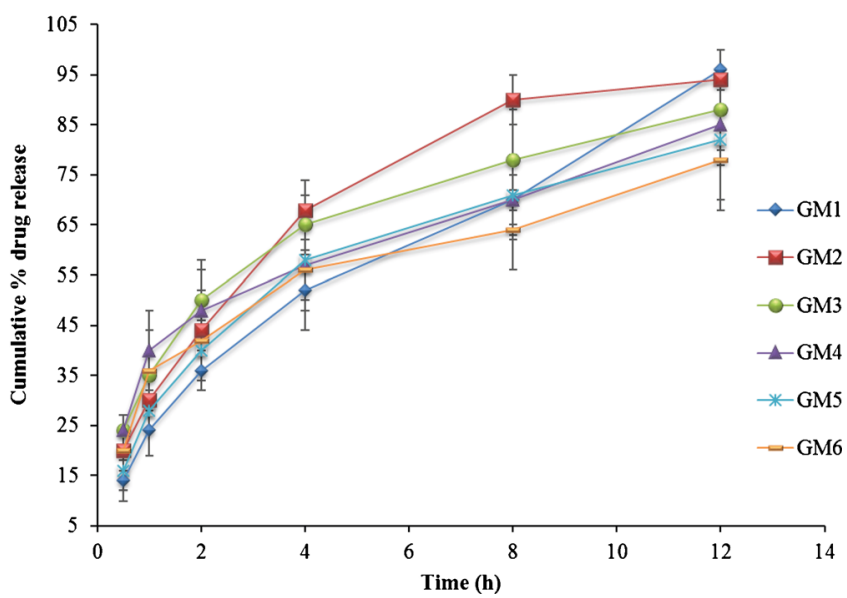

Fig. 7. Drug release and permeation kinetic graph of developed buccoadhesive film. a In vitro zero-order drug release plot of buccoadhesive film b Ex vivo zero-order drug permeation plot of buccoadhesive film

\section{Morphology and Stability}

The physical appearance of the buccoadhesive film was smooth (Fig. 3a). Figure 3b shows SEM photomicrograph of intact buccoadhesive film. The photomicrograph indicated a smooth and well-dispersed matrix system which ensured the successful formulation of a good quality film by solvent casting technique. Abruzzo et al. have reported formation of smooth film of gelatin and chitosan by the same method (18). Film GM6 was subjected to SEM analysis after $12 \mathrm{~h}$ of dissolution and a comparatively rough surface was observed. This is in agreement with the minor erosion behavior of the film as observed in the swelling and dissolution studies. The photograph and photomicrograph of film after $12 \mathrm{~h}$ dissolution study are depicted in subpanels c and d of Fig. 3, respectively.

Buccoadhesive film GM4 was subjected to the stability analysis by keeping the film samples at $4 \pm 0.5$ and $22 \pm 1^{\circ} \mathrm{C}$ for 6 months. Based on the results, films stored at $22 \pm 1^{\circ} \mathrm{C}$ were found to be comparatively stable than the films stored at $4 \pm$ $0.5^{\circ} \mathrm{C}$. No significant difference $(P<0.05)$ was found in the drug release and permeation of the films after 6 months of storage at $22 \pm 1^{\circ} \mathrm{C}$. The results of all tested physicomechanical investigation at different storage conditions are shown in the supplementary materials (Table S-3 and Figure S-4).

\section{CONCLUSION}

Stable polymeric buccoadhesive films of glimepiride were successfully developed employing Methocel, Pluronic F68, and Ultrez-21 polymers. These polymers have noteworthy effect(s) on the physicomechanical behavior (especially film strength, buccoadhesive strength, and tensile strength) of films which was investigated by new instrumental techniques. Methocel exhibited a principal role in the release and permeation characteristics of glimepiride, and zero-order Fickian diffusion was observed in its release/permeation. Electrical, wetting, and adsorption theories were found to be responsible for in vitro buccoadhesion of films. The optimized films exhibited compatibility with probiotic microorganisms. Based on the experimental findings, GM-4 was found to be the optimized formulation which could be promoted for further experimentations.

Table V. Drug Release and Permeation Kinetics of Buccoadhesive Films

\begin{tabular}{|c|c|c|c|c|c|c|}
\hline \multirow[t]{2}{*}{ Kinetic model } & \multirow[t]{2}{*}{ Formulation code } & \multicolumn{3}{|c|}{ Correlation coefficient $\left(r^{2}\right)$} & \multirow[t]{2}{*}{ Korsmeyer-Peppas $(n)$} & \multirow[t]{2}{*}{ Mechanisms } \\
\hline & & Zero order & First order & Higuchi & & \\
\hline \multirow[t]{6}{*}{ In vitro drug release } & GM1 & 0.9713 & 0.9210 & 0.9435 & 0.482 & Fickian \\
\hline & GM2 & 0.9588 & 0.9030 & 0.9233 & 0.348 & Fickian \\
\hline & GM3 & 0.9286 & 0.8108 & 0.9123 & 0.458 & Fickian \\
\hline & GM4 & 0.9511 & 0.9009 & 0.9342 & 0.382 & Fickian \\
\hline & GM5 & 0.9020 & 0.8150 & 0.9045 & 0.480 & Fickian \\
\hline & GM6 & 0.9199 & 0.9012 & 0.9002 & 0.490 & Fickian \\
\hline \multirow[t]{6}{*}{ Ex vivo drug permeation } & GM1 & 0.9003 & 0.8896 & 0.9120 & 0.356 & Fickian \\
\hline & GM2 & 0.9185 & 0.8235 & 0.8997 & 0.358 & Fickian \\
\hline & GM3 & 0.8286 & 0.9101 & 0.8765 & 0.458 & Fickian \\
\hline & GM4 & 0.9111 & 0.8512 & 0.8965 & 0.345 & Fickian \\
\hline & GM5 & 0.9250 & 0.8688 & 0.9045 & 0.490 & Fickian \\
\hline & GM6 & 0.8639 & 0.8286 & 0.8639 & 0.486 & Fickian \\
\hline
\end{tabular}




\section{ACKNOWLEDGMENTS}

Authors are highly thankful to the Director of the CSIRCentral Institute of Medicinal and Aromatic Plants, Lucknow, India for providing necessary infrastructure and facilities under the in-house project OLP-08 to carry out the research work. Authors duly acknowledge Dr. Suaib Luqman for helping us in improving the language of the manuscript.

\section{Compliance of Ethical Standards}

Conflict of Interest All authors declare no conflict of interest in the present investigation.

\section{REFERENCES}

1. Serra L, Domenech J, Peppas NA. Engineering design and molecular dynamics of mucoadhesive drug delivery systems as targeting agents. Eur J Pharm Biopharm. 2009;71(3):519-28.

2. Vishnu YV, Chandrasekhar K, Ramesh G, Rao YM. Development of mucoadhesive patches for buccal administration of carvedilol. Curr Drug Deliv. 2007;4(1):27-39.

3. Vasantha PV, Puratchikody A, Mathew ST, Balaraman AK. Development and characterization of Eudragit based mucoadhesive buccal patches of salbutamol sulfate. Saudi Pharm J. 2011;19(4):207-14.

4. Woertz C, Preis M, Breitkreutz J, Kleinebudde P. Assessment of test methods evaluating mucoadhesive polymers and dosage forms: an overview. Eur J Pharm Biopharm Off J Arbeitsgemeinschaft Pharm Verfahrenstechnik eV. 2013;85(3):843-53.

5. Ammar HO, Salama HA, El-Nahhas SA, Elmotasem H. Design and evaluation of chitosan films for transdermal delivery of glimepiride. Curr Drug Deliv. 2008;5:290-8.

6. Sweetman S. In: Sweetman S, editor. Martindale: the complete drug reference. London: The Pharmaceutical Press; 2007.

7. Cheng W-T, Lin S-Y. Processes of dehydration and rehydration of raffinose pentahydrate investigated by thermal analysis and FT-IR/ DSC microscopic system. Carbohydr Polym. 2006;64(2):212-7.

8. Kianfar F, Ayensu I, Boateng JS. Development and physicomechanical characterization of carrageenan and poloxamerbased lyophilized matrix as a potential buccal drug delivery system. Drug Dev Ind Pharm. 2013.

9. Cavallari C, Fini A, Ospitali F. Mucoadhesive multiparticulate patch for the intrabuccal controlled delivery of lidocaine. Eur J Pharm Biopharm. 2013;83(3):405-14.

10. Avachat AM, Gujar KN, Wagh KV. Development and evaluation of tamarind seed xyloglucan-based mucoadhesive buccal films of rizatriptan benzoate. Carbohydr Polym. 2013;91(2):537-42.

11. Yedurkar P, Dhiman MK, Petkar K, Sawant K. Biopolymeric mucoadhesive bilayer patch of pravastatin sodium for buccal delivery and treatment of patients with atherosclerosis. Drug Dev Ind Pharm. 2013;39(5):670-80.

12. Kianfar F, Chowdhry BZ, Antonijevic MD, Boateng JS. Novel films for drug delivery via the buccal mucosa using model soluble and insoluble drugs. Drug Dev Ind Pharm. 2012;38(10):1207-20.

13. Nafee NA, Ismail FA, Boraie NA, Mortada LM. Mucoadhesive delivery systems. I. Evaluation of mucoadhesive polymers for buccal tablet formulation. Drug Dev Ind Pharm. 2004;30(9):985-93.

14. Patel VF, Liu F, Brown MB. Modeling the oral cavity: in vitro and in vivo evaluations of buccal drug delivery systems. J Control Release Off J Control Release Soc. 2012;161(3):746-56.

15. Brookfield. CT3 texture analyzer operating instructions manual no. M/08-371A0708. USA: Brookfield Engineering Laboratories Ltd; 2011.

16. Sriamornsak P, Wattanakorn N, Takeuchi H. Study on the mucoadhesion mechanism of pectin by atomic force microscopy and mucin-particle method. Carbohydr Polym. 2010;79(1):54-9.
17. Aqil M, Bhavna, Chowdhary I, Sultana Y, Talegaonkar S, Ahmad FJ, et al. Transdermal therapeutic system of enalapril maleate using piperidine as penetration enhancer. Curr Drug Deliv. 2008;5(2):148-52.

18. Abruzzo A, Bigucci F, Cerchiara T, Cruciani F, Vitali B, Luppi B. Mucoadhesive chitosan/gelatin films for buccal delivery of propranolol hydrochloride. Carbohydr Polym. 2012;87(1):581-8.

19. Llabot JM, Palma SD, Manzo RH, Allemandi DA. Design of novel antifungal mucoadhesive films: part II. Formulation and in vitro biopharmaceutical evaluation. Int $\mathrm{J}$ Pharm. 2007;336(2):263-8.

20. Ammar HO, Salama HA, Ghorab M, Mahmoud AA. Implication of inclusion complexation of glimepiride in cyclodextrin-polymer systems on its dissolution, stability and therapeutic efficacy. Int $\mathbf{J}$ Pharm. 2006;320(1-2):53-7.

21. Park J-B, Kang C-Y, Kang W-S, Choi H-G, Han H-K, Lee B-J. New investigation of distribution imaging and content uniformity of very low dose drugs using hot-melt extrusion method. Int $\mathbf{J}$ Pharm. 2013;458(2):245-53.

22. Cides LCS, Araújo AAS, Santos-Filho M, Matos JR. Thermal behaviour, compatibility study and decomposition kinetics of glimepiride under isothermal and non-isothermal conditions. J Therm Anal Calorim. 2006;84(2):441-5.

23. Araújo AAS, Storpirtis S, Mercuri LP, et al. Thermal analysis of the antiretroviral zidovudine (AZT) and evaluation of the compatibility with excipients used in solid dosage forms. Int J Pharm. 2003;260(2):303-14.

24. Santos A, Basílio Jr ID, Souza FS, Medeiros AFD, Pinto M, Santana DP, et al. Application of thermal analysis in study of binary mixtures with metformin. J Therm Anal Calorim. 2008:93(2):361-4.

25. Meher JG, Tarai M, Yadav NP, Patnaik A, Mishra P, Yadav KS. Development and characterization of cellulose-polymethacrylate mucoadhesive film for buccal delivery of carvedilol. Carbohydr Polym. 2013;96(1):172-80.

26. Jug M, Kosalec I, Maestrelli F, Mura P. Development of low methoxy amidated pectin-based mucoadhesive patches for buccal delivery of triclosan: effect of cyclodextrin complexation. Carbohydr Polym. 2012;90(4):1794-803.

27. Nappinnai M, Chandanbala R, Balaijirajan R. Formulation and evaluation of nitrendipine buccal films. Indian J Pharm Sci. 2008;70(5):631-5.

28. Lodhi M, Dubey A, Narayan R, Prabhu P, Priya S. Formulation and evaluation of buccal film of Ivabradine hydrochloride for the treatment of stable angina pectoris. Int $\mathbf{J}$ Pharm Investig. 2013;3(1):47-53.

29. Muzib YI, Kumari KS. Mucoadhesive buccal films of glibenclamide: development and evaluation. Int J Pharm Investig. 2011;1(1):42-7.

30. Nair AB, Kumria R, Harsha S, Attimarad M, Al-Dhubiab BE, Alhaider IA. In vitro techniques to evaluate buccal films. J Control Release. 2013;166(1):10-21.

31. Smart JD. The basics and underlying mechanisms of mucoadhesion. Adv Drug Deliv Rev. 2005;57(11):1556-68.

32. Liu L, Fishman ML, Hicks KB, Kende M. Interaction of various pectin formulations with porcine colonic tissues. Biomaterials. 2005;26(29):5907-16.

33. Maderuelo C, Zarzuelo A, Lanao JM. Optimization of release kinetics from sustained-release formulations using modelindependent pharmacokinetic simulation. J Pharm Sci. 2011;100(8):3260-7.

34. Maderuelo C, Zarzuelo A, Lanao JM. Critical factors in the release of drugs from sustained release hydrophilic matrices. J Control Release Off J Control Release Soc. 2011;154(1):219.

35. Jagannath C, Emanuele MR, Hunter RL. Activity of poloxamer CRL-1072 against drug-sensitive and resistant strains of Mycobacterium tuberculosis in macrophages and in mice. Int $\mathrm{J}$ Antimicrob Agents. 2000;15(1):55-63.

36. Leszczynska K, Namiot A, Cruz K, Byfield FJ, Won E, Mendez $\mathrm{G}$, et al. Potential of ceragenin CSA-13 and its mixture with pluronic F-127 as treatment of topical bacterial infections. J Appl Microbiol. 2011;110(1):229-38. 